Research Article

\title{
Motherhood and higher education in Ghana: Experiences of student-nursing mothers
}

\author{
Patricia Mawusi Amos, Bernard Mensah Amoako, Theresa Antwi and Hannah Amoah \\ Department of Counselling Psychology, University of Education; Winneba, Ghana
}

\begin{abstract}
Education is vital to everyone, but it is significant for girls and women. The importance of education is true not only because education is an entry point to other opportunities, but also because the educational achievements of women can have ripple effects within the families and across generations. However, the effect of the inadequate support system in the University and home on academic performance, childcare and other domestic chores cannot be overemphasised. The purpose of this study was, therefore, to investigate the challenges encountered in school and the home and also to explore the perceived coping strategies adopted by student nursing mothers in a tertiary institution in Ghana. A qualitative approach using the descriptive phenomenological design was adopted. Eighteen participants were drawn from an accessible population of 30 student nursing mothers using a purposive and snowballing sampling method. The study employed a thematic approach to analyze student nursing mothers' responses to interviews conducted. The study revealed a lack of concentration, lack of time to study and unfriendly lecture schedule as some challenging experiences of the mothers. On home challenges, student nursing mothers experienced a decline in marital happiness and inadequate care of older kids. Based on these findings, it may be deduced that the programme structure of the university programmes is not student mother-friendly and that student nursing mothers may have problems with grades and psychological wellbeing. Again, there may be some lack of lactating resources in the institution which students' mothers may have utilized to ease the pressure in nursing of their babies. Recommendations were therefore given in light of the study.
\end{abstract}

Keywords: Higher education, student nursing mother, university, counselling

\section{Introduction}

It is an indisputable fact that women play an essential role in society. It is evident that their roles span from home to the workplace, then to the community they live in. The enormous contributions of women in society have of late improved our social, economic, religious and political lives not excluding the improvement in education (Kapur, 2019).

In the past, men were seen to be holding the fort when it comes to societal issues, taking care of the family economically and making sure that the male child in the family is well educated to inherit the family's properties and taking care of other family members. This event indicates that the role of women was relegated to the background (Bayeh, 2016; Chakrabarti \& Biswas, 2012). But quite recently, the trend is changing. According to Kapur (2019), women are not only seen as role models in the family. But are seen generating income by trading, working in financial and educational institutions and helping to bridge marginalized societies through coaching and counselling.

Acquiring knowledge is essential to the growth and development of a country. Research has indicated that people can obtain knowledge through constant education. Education provides the

\section{Address of Corresponding Author}

Patricia Mawusi Amos, University of Education, Winneba, P. O. Box 25, Winneba, Ghana.

\. pmamos@uew.edu.gh 
skills and expertise that enables the people in a society live better lives and improve their social development (Jekayinfa. 1999). Because of that, the people in a society (both male and female) must gain the knowledge and skills to make their lives worth living. Nevertheless, in the traditional African society, the man is seen as the only capable personality who needs to be educated and earn higher income for the family. The woman who is the heart and keeper of the home must be trained at the kitchen (Mumuni, 2000; Bayeh, 2016; Chakrabarti \& Biswas, 2012). However, quite recently, it has been known that marriage and housekeeping limit the role of women (Asiedu-Akrofi, 1978; Edwards, Hasebe, \& Sakai, 2019).

The role conflict theory was used to underpin the study. Role conflict describes the collision between two or more roles assigned to an individual (Adofo, 2013; Soltani, Hajatpour, Khorram, 2013). Sometimes it may refer to the contradictions individuals find themselves within the same role (Chakrabarti \& Biswas, 2012). Two types of role conflict exist, according to Adofo (2013). In intra-role conflict, there is a contradiction within the same role, and with inter-role conflict, there is a collision between separate or different roles for the same person. Intra role conflict may occur when individuals have varying perceptions about the requirements and prospects that make up a particular role in a society or organization.

On the other hand, the inter-role conflict will occur when the prospects and requirements of one's role contradict with those of others (Cheen Ee, Teoh \& Yen, 2017). For instance, Glady's role as a mother is likely to conflict occasionally with her role as a student (intra role conflict). According to Parson (1971), for society to thrive and function effectively, there has to be an established institution with varying roles and responsibilities. Roles must accompany each institution, and each must perform their functions without waver. This act implies that individuals in the society must perform their duties to the latter and for the society to thrive (Intra role conflict).

The changing roles of women from being housekeepers to both breadwinners and housekeepers in the society has made it necessary for nursing mothers to combine childcare, homecare, career and studies. Although mothers are in school, they will have specific responsibilities to fulfil at home. The question is, do women neglect their families in their quest for knowledge or forget about their higher education entirely and stick to old traditions of keeping the family? Likewise, the recent trend in the world economy has necessitated women to act as co-breadwinners in the family. This calls for more education for women so they can take up the challenge in the workplace. (Dolphyne, 1991; Hossain, Niaz Asadullah, \& Kambhampati, 2019). It has become an unavoidable fact for women to be trained in all spheres of the academic ladder. This will enable them to acquire the requisite knowledge and skills to fit into the competitive and ever-growing economy we find ourselves.

Consequently, the change in the educational reforms; has targeted both men and women and their participation in the educational system (Adusah-Karikari, 2008). These reforms have led to a dramatic increase in the number of tertiary institutions at both regular and distance levels, opening more opportunities for women in particular.

A study of Dankyi and Dankyi (2015), stressed on the need for females to take advantage of Distance Education Programmes, which is a considerable improvement in flexible mode of education for women. Nevertheless, Caplan (1993), notes that the academic tenure clock and women's marital and biological clocks overlap. Due to their marital and reproductive responsibilities, women have had to combine their quest for higher education with childbirth. This has ensured the act of having nursing mothers in our various higher educational institutions. In Ghana, universities gender policy has helped to increase the female enrolment for the past years. For instance, the University of Education, Winneba (UEW) in 2016/2017 academic year enrolled 34676 out, of which $30.55 \%$ (10595) were females (UEW, 2017). In the 2018/2019 academic year, the total enrolment was 69506 out of which 40\% (28033) were females (UEW, 2019) with some being nursing mothers. This has resulted in student nursing mothers struggling to adapt to school situations considering that there is a lack of amenities such as lactation rooms and places of convenience for their baby sitters who accompany them for lectures. This has posed much danger to both the student mothers and babies. Again, leaving the babies in the care of baby sitters at home may also pose many challenges. Furthermore, student nursing mothers psychologically, emotionally and physically become ill-disposed towards their academic work due to the stress and trauma they go through (Egenti \& Omoruyi, 2011; Mamhute, 2011).

In the studies of Dankyi, Dankyi, and Minadzi (2019) and Amos and Manieson (2015), it was concluded that the role conflict experienced by nursing mothers and married women affect their academic performance in school and appreciable performance at home. The struggles they go through include the inability to attend face-to-face lectures regularly, and inadequate preparation 
for examinations. All these challenges affect their learning and level of achievements at the University.

Of late, the enrolment of student nursing mothers has increased due to the introduction of sandwich programmes apart from the distance education programmes already being rolled out. This has brought about an increase in the number of nursing mothers having their babies and caregivers patrolling on campuses looking for a safe place to lay their babies and breastfeed them. Again, some lecturers are seen carrying babies of student mothers so they can sit for lectures and write examinations. A brief survey conducted with the women and the experiences of the researhers due to our constanct interaction with the student mothers indicated that some of them face a lot of challenges regarding the proper care of their babies and also combining their home upkeep, marriage and children with academic work.

Due to these issues, some of them are not able to complete the course or will either defer the course. Those who do complete too, may go home with unsatisfactory grades. It would be noted that several steps have been taken by the institutions such as constant guidance and provision of temporal lactating rooms to enable them cope with the pressure on campus. Again, during orientation, they are being asked to visit the counselling centres of the institutions to disucss their issues with the counsellors. Nevertheless, many are the ones who do not patronise these support systems due to various reasons best known to them. The researchers observations of these phenomenon show that more can be done for these student mothers if their experiences are explored. Though numerous studies have been conducted on student nursing mothers, it has been observed that there is a dearth to that of nursing mothers offering sandwich programmes (summer programmes). This study thus seeks to find out the challenges facing student nursing mothers in higher education in Ghana with regards to those who undergo short courses and summer programmes in Ghanain universities. The study will also ascertain the coping strategies they adopt in managing the challenges. It is hoped that the findings of this study will help the academic institutions find appropriate avenues to assist these student nursing mothers.

The study was guided by the following research questions;

1. What academic challenges do student nursing mothers encounter whiles in school?

2. What challenges in the home prevent student nursing mothers from pursuing their tertiary education?

3. How do student nursing mothers cope with the identified challenges encountered in school and in the home?

\section{Method}

\subsection{Research Design}

The research approach adopted was a qualitative approach using the descriptive phenomenological design. This design was employed for this study given that this issue of nursing mothers experiences in higher education have not been fully explored in Africa especially in Ghana. The adoption of this design assisted the reseachers to explore and describe the lived experiences of the student nursing mothers regarding their stay on campus, their learning situation, challenges and how they were able to cope with their challenges (Christensen, Welch \& Barr, 2017). Furthermore, the descriptive phenomenological design enabled the researchers to understand the challenges facing student nursing mothers in higher education institutions.

\subsection{Participants}

A sample size of 18 participants were purposively selected for the study. Explicitly, the homogenous type of purposive sampling was used. This was because the population of nursing mothers was relatively small, especially when compared to the students' population. Also, because the nursing mothers share the same (or very similar) characteristics in terms of their educational background and situation they find themselves (Elmusharaf, 2012; Flick, 2010). Before the 18 participants were reached, one student-nursing mother was contacted. After interacting with her concerning the study and following due protocols, she then served as a conduit for the remaining 17 participants (snowballing approach).

\subsection{Data Collection}

The study setting was the University of Education, Winneba, which is found in the Central Region of Ghana. The University has four campuses in two regions in Ghana. All campuses have nursing mothers who have enrolled on various programmes of study. The data sources for the study were 
student nursing mothers at the Faculty of Educational Studies from the Winneba campus of the University and 30 student nursing mothers were found accessible for the study. Data were gathered with the help of interview protocols. Some of the main questions for the interview were: "What challenges have you encountered on campus ever since you became a nursing mother?", "How are you managing family life with studies on campus?"

As already noted, interviews were used to obtain the necessary data from the student nursing mothers. The researchers visited all the five departments in the faculty to obtain permission and access to nursing student mothers. Participants were then briefed on the processes involved in responding to the items on the protocol. Questions raised during the debriefing sessions were thoroughly explained to the participants. Each interview session lasted between 20-30 minutes. In other to provide an opportunity for probing and clarification, three participants were interviewed in a day. The data were, therefore obtained within six working days. It would be reiterated that the 18 participants were reached due to saturation.

It would also be emphasized that the participation in this study was voluntarily. Participants were asked to read and sign consent form and during this process, confidentiality and anonymity were assured. More so, participants were assured that in an instance that they felt hesitant to proceed, they should make it known to the researchers in other not to reveal sensitive information they may not be comfortable with. The interview was conducted as follows: One-no-one interview with nursing mothers was conducted in an enclosed but spacious office. The researchers probed, clarified and controlled the participants to be on track/on the subject under discussion. The interview was ended when the saturation point was reached. A tape recorder alongside taking footnotes recorded the interview data. The recorded data were transcribed carefully by listening repeatedly. The transcribed data were ready for analysis by using content analysis strategy.

\subsection{Data Analysis}

Content analysis was conducted using themes identified and developed from the collected data. Coding regimes were used to develop the themes. Coding and forming themes from the data collected were done by reading and re-reading transcribed data, observing similarities and differences to make themes and categories. This was done by the production of codes, demarcation and identification of themes. Footnote taking during the interview session served as additional information to the various themes generated. Trustworthiness of data was ensured through different strategies. These included reflexivity, triangulation of sources of data, peer debriefing, and member checking and an extended stay in the field during the process of data collection. The data were analyzed based on codes in order to ensure the anonymity of the participants. Hence, the researchers used the following codes to analyze the themes: NM1, NM 2, NM3 ... NM18 for interviewees.

\section{Findings}

Data analysis was done in relation to the objectives of the study and response to the research questions, as highlighted in the introduction.

\subsection{Academic challenges student nursing mothers encounter in school}

To find answers to this, three thematic areas as identified from the narrative accounts were presented.

\subsubsection{Concentration and Attention}

Nursing mothers did mention a lack of concentration and not been able to be attentive through out the lecture session. This is what one participant had to say: "As a nursing student mother, it is difficult to nurse a baby as combined to learning. Many at times, concentration during lectures becomes difficult because the mind too will be on the baby left behind" (NM1). Similarly, another nursing mother noted: "I have divided attention as I care for my children and learn at the same time" (NM2). Whiles some nursing mothers lack the concentration and attention whiles in class, for one nursing mother, she reported skipping lectures to take care of her baby by stating that: "Sometimes I skip lectures to take my baby to the hospital when he is sick. And it affects my studies since I can't concentrate that whole period of time (NM4). Whiles some participants (student nursing mothers) mentioned lack of concentration, one particpants on the other hand mentioned the effect of her lack of attention in class. This is what she had to say: "Attention in lectures is limited because I have to give some attention to my crying baby...sometimes, I am unable to take notes during lectures" (NM8). 
From the views of the participants, it would be reiterated that having babies whiles in school implies that the mother may lack some form of attention and concentration in the class due to the constant care the baby may need whiles in the classroom.

\subsubsection{Inadequate Time for Caregiving}

Another emerging theme that popped up was inadequate time for caregiving responsibilities. Some of the participants mentioned that because of numerous workloads on their academics, the attention needed for the babies and other children is inadequate and they feel it is not the best in developing a good relationship between them and the other kids. Just as they are not able to make enough time for the babies, their academic work too suffers because of the enormous workload. This is what one participant reported: "I find it very hard to get time for my son during lectures. Because there are no breaks" (NM5). Another response was this: "I hardly have time for my breastfeeding baby and completing individual and group assignments" (NM6). Based on the the responses made by the student nursing mothers, it would be reiterated that these nursing mothers are saddled with numerous academic works in the classroom and this is limiting the amount of time they spend with their babies and the other kids.

\subsubsection{Inadequate Time for Personal Studies}

It also emerged from the studies that early and late lectures mainly influence inadequate time for personal studies. A participant noted: "Time for lectures (beginning and closure) is affecting my studies greatly" (NM7). Another participant retorted aptly by noting this: "Early and late lectures affect my personal engagements with my children and academic work. This is because, I am always tired to learn after the day's lectures" (NM10). On the other hand, a participant mentioned inability to make time for personal studies because of the children. This is what she had to say: "I am not getting enough time with my studies because of my children......" (NM3).

In summary, it would be emphasized that lack of concentration, inadequate attention for the babies and other kids and also ample time for personal studies are the major challenges student nursing mother face whiles studying in higher institutions.

\subsection{Home Challenges of Student Nursing Mothers}

This research question investigated home challenges facing student nursing mothers in the University. The participants were asked to indicate some home-related problems affecting their studies at the University. During the interview, some of the participants mentioned marital responsibilities and also lack of safety for the other kids who are left at home in the care of the other spouse, family relations or househelps. The first significant revelation made was conjugal responsibilities. One participant stated; "I encounter marital problems..... my husband complains that I don't have time for him and threatened to withdraw his support for my education in the university" (NM11). One of the nursing mother's retorted: "Lack of time and attention for my husband; and that makes me think and unable to focus on my academic work". Another significant finding was children safety in the absence of the mother at home. A participant aptly stated: "I always think about the safety of my children at home" (NM12). This taught of nursing mothers about the safety of their children may result in lack of concentration during lectures. İt would be assumed that student nursing mothers can sit in the lecture hall and may not be able to grasp any concept because of the situation they find themselves.

Again, a participant who looked so stressed noted: "Thinking, nursing, parenting and household chores are affecting my studies in the university" (NM1). However, another participant saw undue pressure from the place of work as having enormous stress on her academic life. She stated: "My work schedules are so tight that I don't even have time to study on my own. Sometimes, my boss also threatens that I should choose between my job and school" (NM4).

\subsection{Coping Strategies of Student Nursing Mothers}

This research question examined strategies adopted by student nursing mothers in managing family life and academic work. Concerning spousal and family support, one participant stated: "The children are left with the father during the weekdays, so I go home during the weekend to prepare food and do other things for them. This help me to have time during the weekdays to learn" (NM17). Another participant also reported: "With the help of my husband, I am able to cope with the family life as well as my studies even though it is not easy at all" (NM18). It also emerged from the narratives that those who could not access the services of caregivers are forced to look for early childhood education centres for their children. A participant said: "I normally send my daughter to a school in order to have my peace of mind to attend lectures" (NM4). Another 
participant also indicates that she usually put her trust in God amid the challenges militating against her family and academic life.

\section{Discussions}

Responses from the student nursing mothers indicate that these mothers in the University face academic challenges such as lack of concentration and attention, inadequate time for caregiving and inadequate time for personal studies. The finding is supported by Amos and Manieson (2015); Najjuma and Kyaruga (2006), who asserted that divided attention over childcare and academic activities, most often leads to lack of concentration to student nursing mothers. Most nursing mothers bring their tender children with or without paid givers to lecture halls. Sometimes, these children are so young to be entrusted in the care of another person, other than their biological mothers. Regular jiggling and irritability of children often distract the attention of mothers from academic activities in lecture halls. This perhaps may influence memorization and recall of facts, thereby affecting their academic performance. Student mothers are so much attached to their children and would sacrifice anything for their children's safety and survival. The finding is also confirmed by Andres and Finlay (2004) who indicated lack of time for studies as one of the major academic challenges facing nursing mothers. This difficulty appears to be prevalent due to compact nature of the school's curriculum. The academic timetable is loaded in such a manner that little break is given to students. Nursing mothers hardly find time to study notes and do individual readings coupled with childcare and maintenance. Sometimes, these nursing mothers with their infant babies are at the clemency of poisonous reptiles and mosquitoes. If student nursing mothers close very late in the evening from lectures, trek long distances to get to their hostels; what time would they be left with for any serious studies?

From the various narratives on home challenges, it could be suggested that conjugal responsibilities, home management and child safety account for significant stress for nursing mothers pursuing various programmes in the University of Education, Winneba. Williams (2007) suggested that choosing to become a mother gives the appearance that a woman is unmotivated, less committed, less interested in doing what she must do to get to the next step on the ladder. However, Egenti and Omoruyi (2011) state that the stress or trauma which nursing mothers have to go through makes them feel psychologically ill-disposed towards the programme. This could lead to termination of the programme. The result further suggests that nursing mothers on daily basis contemplate about their inability to fulfil their marital responsibilities towards spouse while on campus. Furthering education could have profound effect on relationships and marriage among women. Marital happiness appears to decline among couples in which wives were enrolled as students.

It was deduced from the narratives that nursing mothers relied on social and emotional supports from husbands, older siblings and other significant relatives. Most of the participants indicated that their husbands understand the difficulties they are going through and are making conscious efforts to lend support to nursing mothers. It can be argued that husbands' involvement in the student nursing mothers' education would enhance the latter psychological wellbeing for rigorous academic work. Grohman and Lamm (2009) in their study found out that emotional support from husband and peers and time management strategies was used by $93.3 \%$ of nursing mothers. It also emerged from the narratives that those who could not access the services of caregivers are forced to look for early childhood educational centres for their children. This strategy becomes useful when such a child is of school-going age. Finally, when all these strategies fail, the nursing mother is most likely to put her trust in God for a miracle. One of the participants indicated that she normally put her trust in God in the midst of challenges militating against her family and academic life. This response could represent a clear state of hopelessness which could trigger discontinuation from the programme.

\section{Conclusion and Recommendations}

The introduction of sandwich (summer) programmes in Ghanaian universities and the opportunity for working mothers to pursue higher education has increased the enrollement of student nursing mothers. Their daily interaction and activities on campus are few indications of the constant challenges they encounter. This study therefore took a look at the challenges the student nursing mothers experience whiles on campus and some coping strategies they adopt to curb the challenges.

The study proofed that student nursing mothers do not have adequate time both for their academic work and their nursing babies whiles on campus. Their presence on campus too means that the kids at home are left with family members and their spouses and others believe that their 
kids lack proper care because of their absence at home. Based on the findings, it can be concluded that the structure of the university programme is not nursing mother friendly. It can also be concluded that nursing mothers could have problems with grades and psychological wellbeing due to the incenssant pressure they go through from the family and academic work.

In view of the findings, the study recommends that; higher education institutions in Ghana should re-align their course structure to make it more nursing mother friendly. The University should provide permanent lactation rooms for nursing mothers. This could serve as temporal resting rooms for them as they breastfeed their babies. This may go a long way to ease the academic frustrations faced by nursing mothers. However, nursing mothers must keep their priorities straight. They should devise means of childcare and academic work. To overcome home challenges, student mothers should arrange for caregivers to take care of the safety of their children. Alternatively, nursing mothers should visit homes every two-weeks to check on the health and safety of the other children and their spouses. Similarly, regular phone calls to the home would cement good marital relationship and motherly care.

\section{Implications to Guidance and Counselling}

Academic challenges facing nursing mothers suggest that academic orientation programmes being run in the school falter in students' adjustment process, especially among nursing mothers. For this purpose, guidance and counselling programmes should be intensified and encouraged among expectant mothers on campus and those nursing babies. Group counselling on maternal academic stress should be run throughout the academic year. Home challenges are conditions outside the University which could have rippling effects on the psychological states of nursing mothers. In order to address the numerous challenges affecting nursing mothers on campus, prevailing home conditions such as a decline in marital satisfaction and concern of child safety should be examined. If nursing mothers experience marital satisfaction and ascertain child safety, their stress levels would reduce, giving them much study comfort to excel on academic programmes in the University. Finally, student nursing mothers will be able to cope with challenges by receiving social and instrumental support from spouse (e.g. husband) and other family members. Instrumental supports in the form of counselling should also be tailored to the individual needs of student nursing mothers. It would be emphasized that student nursing mothers should be seen as active agents, seeking potential growth and autonomy in personal, social and academic pursuits.

\section{Limitations of the Study}

The complexity of the cultural practices in Ghana and their impact on married and nursing mothers who make up the participants may have some influence on our findings. Participants may have wished to state certain issues bothering them mostly at home, but because of the nature of our culture, these participants may not want to reveal those sensitive information that would mar their relationships in the home. Given this, the researchers may have missed what is most appropriate for this study and also to some of the participants.

It would also be argued that the small sample size and the method of data collection used will not allow for the study to be generalized to a large population. Given this, responses from participants cannot be said to be the views of all student nursing mothers in the University. Future research can take a look at the quantitative approach, which will give all student nursing mothers the chance of being selected for the study.

\section{References}

Adofo, S. (2013). Challenges and coping strategies of student nursing mothers in tertiary institutions in the Greater Accra region of Ghana. Unpublished Thesis, Legon: University of Ghana.

Adusah-Karikari, A. (2008). Experiences of women in higher education. A study of women faculty and administrators in selected public Universities in Ghana. PhD Dissertation.

Amos, P. M. \& Manieson, E. (2015). Issues and challenges confronting married women in tertiary institutions. International Journal of Education, Learning and Development,3(9), 19-27.

Andres, L. and Finlay, F. (2004). Student affairs: Experiencing higher education. Vancouver: University of British Columbia Press.

Asiedu-Akrofi, K. (1978). School administration in modern Africa. Tema: Ghana Publishing Corporation. 
Bayeh, E. (2016). The role of empowering women and achieving gender equality to the sustainable development of Ethiopia. Pacific Science Review B: Humanities and Social Sciences, 2(1), 37-42. https://doi.org/10.1016/j.psrb.2016.09.013

Caplan, P. J. (1993). Lifting a ton of fathers: A woman's guide for survival in the academic world. Toronto: University of Toronto Press.

Chakrabarti, S., \& Biswas, C. S. (2012). An Exploratory analysis of women's empowerment in India: A Structural Equation Modelling Approach. Journal of Development Studies, 48(1), 164180. https://doi.org/10.1080/00220388.2011.615920

Cheen Ee, M. J. Y., Teoh, W. M.-Y., \& Ten, Y. Y. (2017). Role conflict, role ambiguity and role overload: The strains of work-family conflict. The Social Sciences. http://docsdrive.com/pdfs/medwelljournals/sscience/2017/1566-1576.pdf

Christensen, M., Welch, A., \& Barr, J. (2017). Husserlian Descriptive Phenomenology: A review of intentionality, reduction and the natural attitude. Journal of Nursing Education and Practice, 7(8), 113. https://doi.org/10.5430/jnep.v7n8p113

Dankyi, J. K., \& Dankyi, L. A. (2015). Perceived effects of University of Cape Coast distance education on teachers' performance in the basic schools of Kwahu West Municipality. International Journal of Research in Social Sciences, 6, 1-8.

Dankyi, J. K., Dankyi, L. A., \& Minadzi, V. M. (2019). Struggles and coping strategies of student mothers at the University of Cape Coast Distance Education, Ghana. Creative Education, 10, 2484-2494.

Dolphyne F.A.C. (1991). The emancipation of women: An African perspective. Accra: University Press.

Edwards, L. N., Hasebe, T., \& Sakai, T. (2019). Education and marriage decisions of Japanese women and the role of the Equal Employment Opportunity Act. Journal of Human Capital, 13, 260-292. https://doi.org/10.1086/702924.

Egenti, M. and Omoruyi, S. (2011). Challenges of women participation in continuing higher education programme: Implications for adult women counselling and education. Edo Journal of Counselling. http://www.osa.com

Elmusharaf, K. (2012). Qualitative sampling techniques. https://www.gfmer.ch/SRH-Course2012/research-methodology/pdf/Qualitative-sampling-techniques-Elmusharaf-2012.pdf

Flick, U. (2010). An Introduction To Qualitative Fourth Edition. SAGE Publications, 506. https://doi.org/978-1-84787-323-1

Grohman, R., \& Lamm, W. T. (2009). Reasons for student non-attendance at lectures and tutorials by nursing mothers: An analysis. Investigations in University Teaching and Learning, 2(2), 40-51.

Hossain, M., Niaz Asadullah, M., \& Kambhampati, U. (2019). Empowerment and life satisfaction: Evidence from Bangladesh. World Development, 122, 170-183.

Jekayinfa, A. A. (1999). The Role of Nigerian women in culture and national development. Journal of Educational Theory and Practice, 5(1\&2), 22-29.

Kapur, R. (2019). Role of women with the society. University of Delhi. https://www.researchgate.net/publication/331065236_Roles_of_Women_within_the_Society\#f ullTextFileContent

Mamhute, R. (2011). The challenges of pregnant and nursing adult learners: a case study of Morgenter teachers' college. Stellenbosch: Stellenbosch University. (M.Ed-Dissertation).

Mumuni, B. Y. (2000). Factors influencing female enrolment in educationaldan institution in Ghana. A case study of West Mamprusi District in the Northern region of Ghana. Unpublished M. Phil. Thesis, Cape Coast: University of Cape Coast.

Najjuma, S. M. \& Kyarugahe D. T. (2006). Studying and parenting: Experiences of student mothers in Ugandan University. Monograph Series, Number 17.

Parson, T. (1971). The present status of "Structural-Functional" Theory in Sociology. In T. Parsons (Ed.), Social systems and the evolution of action theory (p. 218). New York: The Free Press.

Soltani, I., Hajatpour, S., Khorram, J., \& Nejati, M. H. (2013). Investigating the effect of role conflict and role ambiguity on employees' job stress:Articulating the role of work-family conflict. Management Science Letters, 3(7), 1927-1936. https://doi.org/10.5267/j.msl.2013.06.036

University of Education, Winneba (2017). Vice-Chancellor's annual report. 22nd Congregation. UEW: Winneba. 
University of Education, Winneba (2019). Vice-Chancellor's annual report. 24th Congregation. UEW: Winneba.

Williams, S. A. (2007). Graduate students mothers negotiating academia and family life. New Jersey; Prentice Hall. 